\section{sciendo}

Management Consulting Journal

Volume 1.1 | June 2018

DOI: $10.2478 / \mathrm{mcj}-2018-0002$

ISSN: 2631-987X

(C) 2018 Dr. Julie Hodges. This is an open access article licensed under the Creative Commons AttributionNonCommercial-NoDerivs License (http://creativecommons.org/licenses/by-nc-nd/3.0/).

\title{
Consulting Capabilities for Organisational Change
}

\author{
Dr Julie Hodges, Durham University Business School
}

\begin{abstract}
The aim of this article is to examine the capabilities for consultancy for organisational change. Based on empirical evidence, insight is provided into the capabilities that consultants need in order to be effective in organisational change. These include: building and maintaining relationships; building and sustaining trust; managing emotions; being self-aware; gaining commitment and engagement; being resilient; demonstrating a tolerance for ambiguity and uncertainty; demonstrating political astuteness; managing the power dynamics; and creating effective organisational change conversations. The relative emphasis on each capability will depend upon the situation, but all are vital in consultancy for change.
\end{abstract}




\section{Introduction}

To be able to implement and sustain change successfully requires consultants to possess, what is referred to as, a sort of 'gift' specific to the consulting industry; a 'natural consulting skill' (Kakabadse et al, 2006). It is like being a musician, most people can play badly but it is the people who can play well who can become excellent. To become excellent requires not just skill but specific capabilities: skills, knowledge, attitudes, and experience.

There have been many attempts to define the breadth of capabilities that a consultant needs in order to be considered fully competent with various generic lists (for example, Anderson, 2012). De Caluwe and Reitsma (2010) list ten capability categories which comprise: enterprising; showing resilience; organizing; performing; analysing; considering; facilitating; influencing; managing; and inspiring confidence. Instead of breadth in a large number of capabilities, some researchers suggest the need for deep expertise in a small number of areas. Kenton and Moody (2003), for example, describe three areas where consultants need to be skilled: personal and interpersonal effectiveness; working as an agent of change; and consulting skills. In a survey of consultants Kakabadse and colleagues (2006) found that the following five skills were necessary to become an efficient consultant: experience; functional skills; ability to listen and question; objectivity; and self-awareness. In order to meet the challenge of consulting Wickham and Wickham (2008) say that the consultant must develop a skill profile that allows them to call upon abilities in three key areas: an ability to manage the consulting exercise as a formal project; the ability to manage the analytical skills necessary to gain an understanding of the client business and the possibilities it faces; and an ability to communicate ideas and positively influence others. Such expertise in a small number of specific areas enables a consultant to build in-depth capabilities rather than be a 'Jack [or Jill] of all trades'.

Trying to identify relevant capabilities for consultancy for change from the vast lists, which prevail, is a daunting prospect. In an attempt to address this Wilcox and Jenkins (2015) suggest grouping capabilities under the four headings of exploration, envisioning, engagement, and execution. Such groupings are helpful in that they tend to mirror the key stages of most consultancy approaches but are nevertheless vague and generic.

\section{Consultancy Capabilities for Organisational Change}

To identify the most relevant capabilities, a survey was conducted with over one thousand consultants from 20 countries and 25 different organisations, along with over 500 client managers from 30 organisations to help identify the key capabilities. Internal consultants accounted for $45 \%$ of respondents and external consultants $55 \%$. The managers were primarily from the private sector $(70 \%)$, while the majority of consultants who responded specialised in Organisation Development (40\%); Human Resources (20\%); Technology (15\%); Operations (15\%); and Finance (10\%). 
The sample for the study was constructed using professional and informal networks which is an approach regularly employed as a means of gaining access (Gummesson, 2000). A snowball technique was used so that individuals who agreed to participate recommended other potential respondents (Atkinson \& Flint, 2001). One danger of "snowballing" is the potential for cloned respondents with each person at risk of being much like the next in terms of traits, interests, or patterns. To prevent this happening, ten separate "snowballing" chains were launched, each starting from a different networking source. Participants were asked to rank in order of importance the most relevant capabilities required for consultancy for change. The top ten capabilities identified were: building and maintaining relationships; developing and sustaining trust; managing emotions; gaining commitment and engagement to change; facilitating creative dialogue; resilience; having a tolerance for ambiguity and uncertainty; having political astuteness; managing power dynamics; and being an effective communicator. Based on the high-level findings from the survey we will now briefly describe each of these capabilities and their importance in conducting consultancy for organisational change based on the survey findings and further research.

\section{Building and Maintaining Relationships}

As one participant pointed out, "Consultancy is about people and the consultant's role is to firstly establish a sound relationship with the client and attempt to make them feel comfortable with the consultant and the consultancy process". This foundation is critical to the openness, sharing, and honesty that are necessary during organisational change (Jamieson and Armstrong, 2010). The need to create a sound relationship is vital. The key to a successful relationship between consultants and clients depends on the proactive behaviour of the consultant, which means that the consultant needs to think even of those needs and requirements of which a client has not been aware, and helps the client to see such needs and possibilities. To achieve this requires a positive clientconsultancy relationship which is built on trust.

\section{Developing and Sustaining Trust}

A number of respondents in the survey pointed out that a client's willingness to share information will depend on how much they trust the consultant. To reinforce the importance of trust, Cope (2010) has developed a helpful mnemonic of TRUST:

- Truthful - the consultant and the client must be truthful to one another.

- Responsive - the consultant needs to engage totally in the client's world.

- Uniform - a consultant must be consistent in their ideas and attitudes towards the engagement.

- Safe - given some of the emotions a client may feel it is important that the client feels safe working with the consultant.

- Trained - it may sound obvious, but it is important that the client believes the consultant is competent in the area of expertise that they are being consulted about. This will be based on their work experience and credibility, and if they are external consultants, then also on the reputation of the consulting firm for which they work. 
The ability of a consultant to build trust and gain the credibility of the client is a key factor for building an effective client-consultant relationship.

\section{Managing Emotions}

Participants emphasised that the relationship existing between consultants and clients involves an emotional dimension that must be managed. In support of this the relationship between the consultant and the client has been described as an 'emotional duet', in which the consultant has to learn to 'recognise, deal with and respond to the client's emotions' (Stumpf and Tymon Jr, 2001: 49). Lundberg and Young (2001) go as far as to say that consultants who are called in to provide expertise and solutions on pragmatic problems such as change, are in fact implicitly called in to provide emotional support. Indeed, organisational change is not only about dealing with the change but also about dealing with feelings and emotions of the different members involved in the process (Hodges, 2016). This is important to recognize because the consultant needs to avoid finding themselves in a situation where, although a good piece of consultancy was delivered, the client is disappointed because emotions were not managed carefully.

Emotions are involved throughout a consultancy assignment; hence consultants must be able to create a climate where clients feel that they can trust the consultant. However, in order to reach such a stage, the consultant must dedicate their full and undivided attention to the client and their objectives and place the client's interest ahead of their own. This involves consultants carefully managing and understanding their own emotions as well as those of the client. So consultants need to be aware of their own abilities and emotions and know their strengths and areas for development.

\section{Gaining Commitment and Engagement}

Getting commitment to a change is part of the process of engaging people in organisational transformations (Hodges, 2018). A consultant who is trying to help an organisation to go through a transformation, needs to help people not only to understand it but also to engage and be committed to it. Participants in the survey described this in terms of 'getting buy-in' for change. Engagement and commitment need to come primarily from the client but also from key stakeholders. For example, frontline employees are the ones responsible for behaving in ways conducive to proposed change and often have to learn new ways of doing things. Commitment to change is therefore an important enabler of change, if employees are not engaged then very little will change. One way to build commitment is for consultants and clients to create an environment in which the people most affected by change have a role in shaping it. This involves helping individuals to understand what the rationale is for the change. Involving front-line staff in the diagnosis and joint problem-solving in order to identify solutions will help to gain commitment at an early stage because people are more likely to react positively if they have been involved in defining the solution rather than having a solution imposed on them. 


\section{Resilience}

Survey participants stressed the need for consultants to be resilient. This requires developing an ability to thinking positively, maintaining perspective, developing a strong network of supportive relationships and taking care of one's mind and body. In an article entitled, 'Increase your resilience to change' Proctor (2014) identifies the characteristics of resilient people as optimistic, self-assured, focussed, open to new ideas, willing to ask for support, structured, and proactive. These components of resilience all play a vital role in enabling consultants to manage stressors in a proactive, adaptive, and positive way. Resilient consultants are able to draw on these qualities at the right time and understand when, for example, being proactive is more important than seeking support. Resilience can help to maintain higher performance levels, improve a consultant's sense of wellbeing, and aids them in coping with fluctuating emotions. It also helps them to deal with different types of clients and organisational transformations within different contexts without being overwhelmed.

\section{Tolerance of Ambiguity and Uncertainty}

Participants emphasised that consultants must be able to cope with ambiguity and uncertainty. Ambiguous situations can be defined as completely new situations with no familiar cues or precedents, or as apparently insoluble situations which cannot be solved in the usual way. Such ambiguity creates uncertainty and is uncomfortable and can lead to individuals wanting to quickly resolve issues. The desire to achieve quick solutions may be compounded by a client who questions the capability of the consultant when the consultant responds to the client's 'what's next' questions with 'I don't know' or 'I am not sure where this is going at present'. Rather than agreeing to a quick fix, tolerating ambiguity means being comfortable during a period of uncertainty and taking time to delve into the root causes of an issue.

\section{Political Astuteness}

Just providing the right solution is not enough; survey participants highlighted that consultants have to be able to deal with the politics within the client organisation. Organisational politics are often described as a turf game involving a competition of ideas (Buchanan and Badham, 2009) which consultants may be forced to play. Politics are, however, a naturally occurring phenomenon in organisations and are often resistant to attempts to stifle or eradicate them. Rather than attempting to do so, the more effective response is for consultants to recognise and address them when appropriate. There is, therefore, a need to learn how to read the political context of a change initiative, its political manoeuvring, and informal social network, in order to bring about the desired outcomes. 


\section{Managing the Power Dynamics}

Participants in the survey emphasised that consultants need to know where the power lies when dealing with organisational change, which means not only 'positional' (appointed) power but also 'relational' (people) power, since without this knowledge the progress of change can be severely impeded. Consequently, it is important to know who has power, how to recognize how other people exercise their power, and what power tactics to use. Robbins and colleagues (2010) have identified nine distinct tactics from the research which are:

1. Legitimacy - relying on one's position of authority and stressing that a change is in accordance with organisational policies and rules.

2. Rational persuasion - presenting logical arguments and factual evidence to demonstrate that a change is reasonable.

3. Inspirational appeals - developing emotional commitment by appealing to an individual's values, needs, hopes and aspirations.

4. Consultation - increasing an individual's motivation and support by involving them in deciding how the change will be achieved.

5. Exchange - rewarding an individual with benefits or favours in exchange for supporting a change.

6. Personal appeal - asking for compliance based on friendship or loyalty.

7. Ingratiation - using flattery, praise, or friendly behaviour prior to making a change.

8. Pressure - using warnings, repeated demands, and threats.

9. Coalitions - enlisting the aid of people to persuade an individual or assuring the support of others as a reason for an individual to agree to a change.

"Some tactics are more effective than others. Specifically, rational persuasion, inspirational appeals and consultation tend to be most effective, while pressure tends to backfire and is the least effective tactic. Consultants need to actively use such tactics to effectively manage the power dynamics in a client organisation."

\section{Creating Effective Organisational Change Conversations}

The ability to create organisational change conversations is a core element of consultancy for change which survey participants highlighted as a key capability. This can be achieved through effective listening, questioning, and summarising.

\section{Listening}

Consultants need to be careful not to scare clients with an uninterrupted flow of words and ideas but rather should take time to listen. Tuning in and listening actively will connect a consultant more to their client. Listening is a complex activity that involves different modes - 'listening about' and 'listening for' (Brownell, 2015). 'Listening about' is often value laden and may lead to questions such as, "Do I like what this person is saying?"; "Do I believe it?"; "Do I have evidence to refute it?". 'Listening for', on the other hand, is often about hearing possibility and opportunity: "What are they saying?" "Do I understand it from their perspective?"; "How does that relate to what I know?". 
'Listening for' is listening actively without judgement. Active listening involves paying attention to the client, without interrupting but instead making sounds occasionally to indicate understanding or encouragement, maintaining eye contact, looking interested, being interested and being at ease. It means that the person talking feels that the listener is fully present and not being distracted, such as by checking their phone for messages. Listening also means being aware of the non-verbal behaviour of the speaker, noticing their emotional cues, such as facial expressions which can provide information about how the speaker is making sense of the discussion and allow the consultant to tailor their responses and questions. Consultants should also listen for 'pings' or 'hooks' to enable them to identify what to hang their next question on, such as the person saying, 'I have always had concerns in that area'. Active listening is closely tied up with questioning.

\section{Questioning}

Effective questioning involves asking open questions (such as when, where, what, how) to obtain more information and using reflecting and closed questions (for example, is that right?) to obtain confirmation. If a client does not answer a question immediately (especially an open-ended one), consultants should not rush in and fill the space - there is power in silence, especially with level three questions when the client is likely to need time to think about their answer.

\section{Summarising}

Along with listening and questioning consultants need to summarise or paraphrase what has just been said and also recognize feelings, for instance 'You seem very angry about ....' or 'So, let me reflect back to you what you have just said to check that I understand correctly...'. Summarizing is also a good technique for moving a conversation forward. Listening, questioning, and summarising may appear to be basic skills but are very powerful if used effectively and actively - which can be harder to do and thus requires practice and patience.

\section{Summary}

There are a variety of capabilities that must be grasped in order to become an efficient consultant. In this article we have highlighted the importance of capabilities required by consultants, which are: building and maintaining relationships; managing emotions; gaining commitment and engagement; being resilient; having a tolerance for ambiguity and uncertainty; being political astute; managing power dynamics; and facilitating effective organisational change conversations. The level of expertise and the mastery of certain skills will fluctuate in relation to the level at which consultants operate.

Consultants operating at a strategic level will need to have a depth of experience in the relevant capabilities; while those working at other levels will need to demonstrate the core levels of skills, tools, techniques required; for those who are relatively new to consultancy they will need to build experiences to develop a full portfolio of skills, tools 
and techniques to operate at higher levels. The relative emphasis on each capability will depend upon the situation, but all are vital in consultancy for change.

The research provides some practical implications for the development of consultants. First, the capabilities identified provide a helpful framework for consultant trainers to use in development activities. Second, consultants can benchmark themselves against the capabilities and identify their strengths and areas of development; and third, they can be used to enhance internal consultancy skills.

Further information on capabilities for consultancy can be found in Hodges, J. (2017) Consultancy, Organisational Development and Change. London: Sage. 


\section{References}

Anderson, D. (2012) Organisation Development: The Process of Leading Organisational Change $\left(2^{\text {nd }}\right.$ ed): London: Sage.

Brownell, J. (2015). Listening: Attitudes, principles, and skills, London: Routledge.

Buchanan, D.A. and Badham, R.J. (2009) Power, Politics and Organisational Change. $\left(2^{\text {nd }}\right.$ ed $)$. London: Sage.

Cope, M. (2010) The Seven Cs of Consulting. London: FT/Prentice Hall.

De Caluwé, L \& Reitsma, E (2010) "Competencies of Management Consultants: A Research Study of Senior Management Consultants," in Buono, A \& Jamieson, D (eds.), Consultation for Organisational Change. Charlotte, NC: Information Age Publishing, 15-40.

Hodges, J. (2018) Engaging Employees in Organisational Change, London: Routledge (to be published August 2018).

Hodges, J. (2016) Managing and Leading People through Change, London: Kogan Page.

Jamieson, D. \& Armstrong, T. (2010) 'Consulting for change' in Buono, A \& Jamieson, D. (2010) Consultation for organisational change. IAP: NC, p 3- 13.

Kakabadse, N., Kakabadse, A. \& Louchart, E. (2006) 'Consultant's role: a qualitative inquiry from the consultant's perspective', Journal of Management Development, 25(5): 416-500.

Kenton, B. \& Moody, D. (2003) The Role of the Internal Consultant. London: Roffey Park Institute.

Proctor, A (2014) 'Increase your Resilience to change' Available at https://www.linkedin.com/pulse/20141209100529-8521084-increase-your-resilience-tochange

Robbins, S.P., Judge, T.A. and Campbell, T.T. (2010) Organisational Behaviour, Essex, FT/Prentice Hall.

Stumpf, S.A. and Tymon, Jr, W.G. (2001) "Consultant or entrepreneur? Demystifying the "war for talent", Career Development International, Vol. 6 No. 1, pp. 48-55.

Wickham, P \& Wickham, L. (2008) Management Consulting: Delivering an Effective Project. ( $3^{\text {rd }}$ ed) London: Prentice Hall.

Wilcox, M. and Jenkins, M. (2015) Engaging Change: A people-centred approach $t$ business transformation. London: Kogan Page. 